\title{
Significance of body size to the interaction between a larval fish (Mallotus villosus) and a vertebrate predator (Gasterosteus aculeatus)
}

\author{
P. Pepin ${ }^{1}$, T. H. Shears ${ }^{1}$, Y. de Lafontaine ${ }^{2, *}$ \\ ${ }^{1}$ Department of Fisheries and Oceans, Science Branch, PO Box 5667, St. John's, Newioundland, Canada A1C 5X1 \\ ${ }^{2}$ Pêches et Océans Canada, Institut Maurice Lamontagne, C.P. 1000, Mont-Joli, Québec, Canada G5H 3Z4
}

\begin{abstract}
We investigated the influence of variations in the size of prey (Mallotus villosus) and a vertebrate predator (Gasterosteus aculeatus) on larval fish mortality rates during the period of yolk absorption using mid-size mesocosms $\left(2.7 \mathrm{~m}^{3}\right)$. Increasing predator size increased mortality rates of capelin larvae. Variations in larval capelin size resulted in 2 distinct patterns. Between experimental trials, greater mean size of larval capelin in the mesocosm reduced mortality due to predation. Within an experimental mesocosm, larger larvae suffered higher mortality than smaller individuals. Contrasting patterns of size-dependent vulnerability to predation reflect the hierarchy of processes that determine the probability that a larval fish will be preyed upon. The broad scale response of the predator was determined by the mean relative sizes of prey and predator which govern the average probabilities of encounter, attack and capture. Within the search ambit of a predator (e.g. area or volume searched within a complete diurnal foraging cycle) active prey selection for larger prey due to either greater visibility or higher energy reward was an important factor. A comparison of our results with estimated predation rates by the jellyfish Aurelia aurita indicates that at a similar size a gelatinous zooplankter consumes fewer larvae than a stickleback and is a less efficient predator as measured by the energy ingested relative to energy demands. For both vertebrate and invertebrate predators, the ratio of prey to predator lengths was a strong predictor of the daily mortality rate due to predation. Relative prey-predator sizes may provide a useful perspective to assess changes in larval fish vulnerability as they grow through a predator field.
\end{abstract}

\section{INTRODUCTION}

Cumulative survival during the early life history of fish is influenced by both growth and mortality rates (Houde 1987, Beyer 1989, Pepin 1991). Growth rates have been shown to vary in direct relation to prey availability (Houde \& Schekter 1980, Werner \& Blaxter 1980, Checkley 1984). Population losses result from starvation (O'Connell 1980, Hewitt et al. 1985), transport (e.g. Bakun \& Parrish 1982) and predation [see Purcell (1985) and Bailey \& Houde (1989) for reviews].

Two major points can be drawn from the information currently available on predation of larval fish. First, laboratory and field studies have shown that both

\footnotetext{
- Present address: Environment Canada, Centre St-Laurent, 105 McGill, $4^{\text {eme }}$ Etage, Montreal, Québec, Canada H2Y 2E7
}

invertebrate (Theilacker \& Lasker 1974, Bailey \& Batty 1984, Purcell et al. 1987, de Lafontaine \& Leggett 1988) and vertebrate (Hunter \& Kimbrell 1980, Hunter \& Dorr 1982, Christensen 1983, Alheit 1986, Folkvord \& Hunter 1986, Pepin et al. 1987, Fuiman \& Gamble 1988, 1989, Fuiman 1989) predators can feed heavily on the early life history stages of fish. Second, predation rates on fish larvae by invertebrate carnivores tend to decrease as larvae increase in size (Theilacker \& Lasker 1974, Bailey 1984, Bailey \& Batty 1984, Purcell et al. 1987) whereas the predation rates on fish larvae by vertebrate predators first increase as larvae increase in size (Folkvord \& Hunter 1986, Pepin et al. 1987, Fuiman 1989, Fuiman \& Gamble 1989) but eventually decrease as the larvae become more capable of avoiding attacks (Fuiman 1989). The pattern of vulnerability of larval fish to different predator types is 
similar to that of herbivorous zooplankton subject to predation by planktivorous fish and invertebrate carnivores in freshwater plankton communities (Brooks \& Dodson 1965, Kerfoot 1987).

Vulnerability of prey to a predator is generally assumed to be a dome-shaped function about a mean size [e.g. 5 to $7 \%$ of the predator's body length (Kerr 1974)] (Pearre 1986, Bailey \& Houde 1989). Below the predator's optimum prey size, increasing prey size will result in increased vulnerability whereas the opposite is true above the predator's optimum prey size. The apparent dichotomy in experimental results using vertebrate and invertebrate predators of fish larvae may result from differences in the relative sizes of prey and predator. For example, in the studies by Folkvord \& Hunter (1986), Pepin et al. (1987), and Fuiman \& Gamble (1989), which use fish predators, fish larvae are generally less than $10 \%$ of the predator's body length whereas in studies by Theilacker \& Lasker (1974), Bailey (1984), and Bailey \& Batty (1984), which use invertebrate predators, larval fish are generally larger than $10 \%$ of the predator's body length. One may ask whether the apparent dichotomy in experimental results would persist if vertebrate predators were of size similar to the many invertebrate predators previously studied (Theilacker \& Lasker 1974, Möller 1980, Bailey 1984, Bailey \& Batty 1984, Purcell et al. 1987, de Lafontaine \& Leggett 1988).

To assess whether the observed differences in vulnerability of larval fish to vertebrate and invertebrate predators is dependent on the relative sizes of prey and predator, we undertook an experimental study of the effects of prey and predator size on the vulnerability of larval capelin Mallotus villosus to predation by a small vertebrate predator, the three-spine stickleback Gasterosteus aculeatus. Larval capelin provide a basis for comparison with other species because they have several morphological similarities to other clupeoid larvae (e.g. herring, anchovy) that have been studied extensively with respect to their vulnerability to predators (Theilacker \& Lasker 1974, Bailey \& Batty 1983, Folkvord \& Hunter 1986, Purcell et al. 1987, Fuiman \& Gamble 1988, 1989, de Lafontaine \& Leggett 1988, Fuiman 1989). Sticklebacks were chosen as model predators because of their potential importance as consumers in coastal marine systems (e.g Vleit 1970, Wooton 1976, Powles et al. 1984, Williams \& Delbeek 1989) as well as their small size (adult length: 30 to $70 \mathrm{~mm}$; Wooton 1976) which is comparable to that of many invertebrate predators used in other studies of predation on larval fish (Theilacker \& Lasker 1974 , Möller 1980, Bailey \& Batty 1983, 1984, Bailey 1984, Purcell et al. 1987, de Lafontaine \& Leggett 1988). Furthermore, the methodology, prey species, developmental stage, and stocking densities used in this study provide a direct comparison to an earlier study by de Lafontaine \& Leggett (1988) of predation by a medusae Aurelia aurita, to which we will contrast our results.

Throughout this study, we use length as a measure of prey and predator size and as the organism's characteristic against which vulnerability of fish larvae to predation is assessed. The importance of size in determining predator-prey interactions in pelagic ecosystems has been highlighted in many studies (Silvert \& Platt 1978, Pearre 1986, Dickie et al. 1987). Organism length is used extensively in studies of larval fish primarily because it is easily measured (e.g. Smith \& Richardson 1977) but also because it is a good correlate of foraging ability (MacKenzie et al. 1990). vulnerability to predation (Bailey \& Batty 1983, Folkvord \& Hunter 1986, Pepin et al. 1987, Miller et al. 1988 ) and vital rates (Houde 1989, Pepin 1991, Pepin \& Myers 1991). Other characteristics (e.g. activity, condition, distribution, pigmentation) may influence vulnerability of fish larvae to predators but body length remains a predominant determining variable (Bailey \& Houde 1989)

\section{MATERIALS AND METHODS}

Laboratory mesocosms consisted of 4 or 6 fibreglass flat-bottomed tanks $1.4 \mathrm{~m}$ diameter and $1.75 \mathrm{~m}$ deep with a volume of $2.7 \mathrm{~m}^{3}$. We conducted our experiments in large experimental mesocosms because previous studies have demonstrated that increasing container size provides conditions better suited to the study of predation by active predators than small aquaria or laboratory containers (de Lafontaine \& Leggett 1987, Gamble \& Fuiman 1987). Each mesocosm was lined with a cylindrical black nitex enclosure (153 $\mu \mathrm{m}$ mesh) equipped with a cod-end. At the start of each experimental trial tanks were filled with fresh sea water filtered through $150 \mu \mathrm{m}$ nitex mesh to prevent large organisms from entering the enclosures. Temperature was measured at the start and end of each experimental trial. Temperature during the experiments was $13^{\circ} \mathrm{C}(\mathrm{SD}=1.3)$ and seldom increased by more than $1.5^{\circ} \mathrm{C}$ during the course of a trial. Light was provided on a $12 \mathrm{~h}$ light: $12 \mathrm{~h}$ dark cycle by 4 fluorescent tubes placed $1.5 \mathrm{~m}$ above the water's surface.

Capelin larvae used in the experiments were obtained from laboratory incubations of naturally spawned capelin eggs. Hatching and emergence occurred over a 3 to $4 \mathrm{wk}$ period. During the incubation period, batches of eggs and gravel were vigorously mixed once or twice daily to obtain emergence of larvae from the gravel. Actively swimming larvae were removed and placed in $40 \mathrm{l}$ glass aquaria containing filtered sea water. Each aquaria was dated to permit 
monitoring of the post-emergence age and condition of larvae. All larvae used in the experiments were recently hatched (median post-emergence age: 1 to 5 d). We were unable to control the size of larvae because of daily variations in emergence rates as well as larval characteristics. However, by using capelin larvae of different post-hatch ages in different experimental trials we were able to obtain variations in the size and degree of yolk absorption that would occur in cohorts emerging from spawning beaches (e.g. Frank \& Leggett 1981). Less than $0.5 \%$ of capelin larvae used in these experiments had fully absorbed their yolk-sac. The period of yolk absorption is a stage during which potential effects of variations in food availability can be overlooked because energy sources are endogenous. Therefore, this represents an ideal period to study how changes in vulnerability are related to larval and predator characteristics and during which starvation should not be significant.

Sticklebacks were obtained from a salt water inlet (28 to $30 \%$ ) using a beach seine with $7 \mathrm{~mm}$ mesh. Fish were acclimated to laboratory conditions in $280 \mathrm{l}$ fibreglass containers with running sea water for at least 6 mo prior to the experiments. The sticklebacks were fed a variety of adult Artemia sp., ground fish and capelin eggs and larvae during their captivity.

We conducted 10 experimental trials. For each trial, the protocol consisted of placing 500 capelin larvae into each of 4 or 6 tanks. Capelin larvae were aspirated into a wide-bore pasteur pipette, counted and placed into $1 \mathrm{l}$ beakers. No more than 100 larvae were placed into each beaker. Sealed beakers were then placed in the experimental mesocosm for $1 \mathrm{~h}$ to allow temperature acclimation. The initial physical condition of the larvae was assessed by keeping at least 100 larvae preserved in $4 \%$ buffered formaldehyde solution. Rotifers (Brachionus plicatilis) were added to each mesocosm at a concentration of $401^{-1}$ to assure that larvae which might exhaust their yolk-sac would have food available. Predators were starved for $24 \mathrm{~h}$ before experimental trials to provide a constant initial hunger level. A single naive stickleback (i.e. one that had not been used in any experimental trial but which had been exposed to capelin larvae as prey) was added as predator in each of 2 or 4 tanks chosen at random. The 2 remaining mesocosms were used as controls. Each experimental trial lasted $24 \mathrm{~h}$ to provide a complete diurnal cycle. Predators were then removed from the tanks and measured for standard length. The enclosures lining each tank were lifted out of the tank, thoroughly rinsed, and the contents of the cod-end preserved in $4 \%$ buffered formaldehyde. The number of larvae recovered from each tank was determined Physical characteristics of larvae (standard length yolk-sac diameter, eye diameter, depth of pectoral girdle) were measured to the nearest $0.1 \mathrm{~mm}$, using an image analysis system, for at least 100 preserved specimens taken at the start of the experiment as well as at least 100 larvae recovered from the control mesocosm and as many survivors as possible (range: 3 to 60 larvae) from the mesocosms with predators. Yolk-sac diameter was used to assess the proximity to yolk absorption and condition (Westernhagen \& Rosenthal 1981), eye diameter can be a measure of the image visible to the predator (e.g. Zaret 1972, Wright \& O'Brien 1982), and the depth of the pectoral girdle can provide a measure of body development in relation to body length.

The instantaneous daily mortality rate due to predation $\left(Z\right.$ in $\mathrm{d}^{-1}$ ) was calculated as

$$
Z=-\left\lceil\frac{\ln \left(N_{t}^{\mathrm{p}} / N_{0}\right)-\ln \left(N_{t}^{\mathrm{c}} / N_{0}\right)}{t}\right]
$$

where $t=$ time interval in $\mathrm{d}, N_{0}=$ no. of larvae at time 0 , and $N_{t}^{\mathrm{p}}$ and $N_{t}^{\mathrm{c}}=$ no. of larvae recovered on Day $t$ in tanks with and without predators respectively. Eq. (1) corrects for depletion of larvae during the experiment in which ingested prey are not replaced and also accounts for losses in the control tanks (Royama 1971).

Daily predator ingestion rates (I in larvae predator ${ }^{-1}$ $\mathrm{d}^{-1}$ ) were calculated as

$$
I=N_{0}\left(1-e^{-Z / P}\right)
$$

where $Z$ = instantaneous daily mortality rate due to predation and $P=$ number of predators, in this case $P=1$.

The analysis performed using Eqs. (1) \& (2) represent the minimum mortality and ingestion rates due to predation because it is not known whether the number of larvae lost in the controls would represent larvae eaten in the trials containing predators.

\section{RESULTS}

Length of capelin larvae used in the experiments ranged from 3.9 to $6.7 \mathrm{~mm}$ (mean lengths ranged from 5.0 to $5.9 \mathrm{~mm}$ ). Less than $0.5 \%$ of larvae had fully resorbed their yolk. The developmental state of the larvae placed into the mesocosms was closely related to their length. Yolk-sac diameter decreased as larval length increased $[\phi=0.99-0.142 L, r=-0.69, p<0.001$, $\mathrm{n}=950$, where $\phi=$ diameter of yolk-sac $(\mathrm{mm}), \mathrm{L}=$ length of the larva ( $\mathrm{mm})$, and SE of intercept and slope coefficients are 0.026 and 0.048 respectively] (Fig. 1). The depth of the pectoral girdle was significantly correlated with larval length $(r=0.16, p<0.01, n=950)$ 


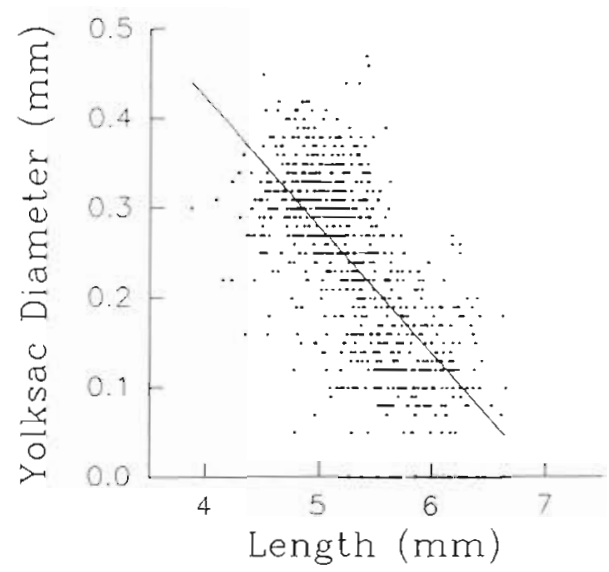

Fig. 1 Mallotus villosus. Yolk-sac diameter in relation to length of capelin larvae

but the low $\mathrm{r}^{2}(2.6 \%)$ precludes any useful interpretation regarding developmental changes. The eye diameter, which may influence the visual image perceived by the predator (Zaret 1972, Wright \& O'Brien 1982), showed no significant relationship with larval fish length $(r=-0.03, p>0.2, n=950)$.
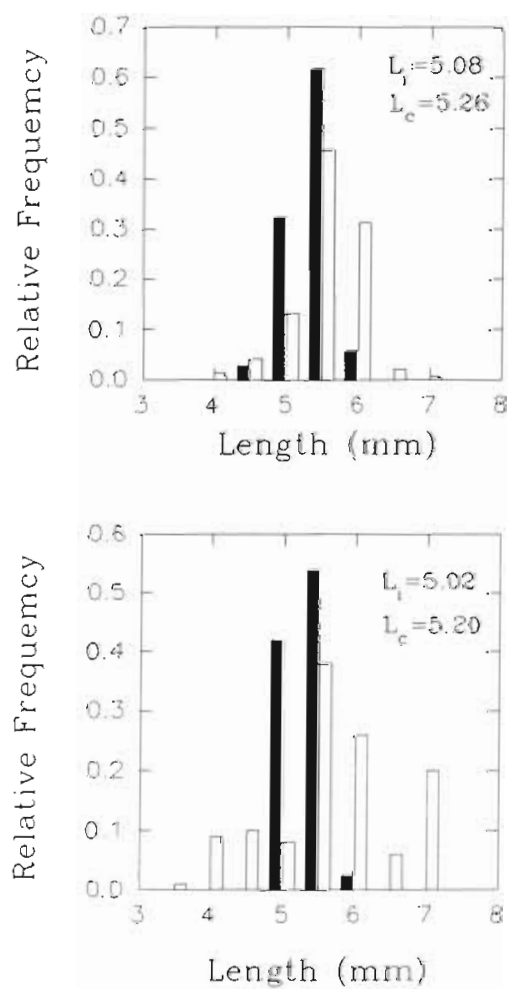

Fig. 2. Mallotus villosus. Relative length-frequency distribution of capelin larvae at start of an experimental trial (black bars) and from the control mesocosms at end of an experimental trial (open bars) for 2 representative treatments. Mean larval lengths from the initial sample $\left(L_{1}\right)$ and control mesocosms $\left(L_{c}\right)$ are in the upper right corner of each panel

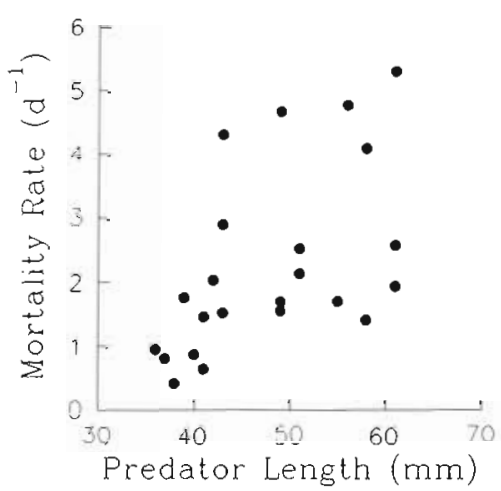

Fig. 3. Mallotus villosus, Gasterosteus aculeatus. Mortality rate $(Z)$ in relation to predator length

Mean mortality rate of larval capelin in the control containers was 0.16 ( $\mathrm{SE}=0.03$ ) and showed no significant relationship with initial larval characteristics. Fig. 2 shows examples of the length-frequency distribution of capelin larvae from the initjal and control samples. Mean length of capelin larvae after $24 \mathrm{~h}$ in the mesocosms was always greater than mean larval length in the initial sample. The average difference in length was $0.18 \mathrm{~mm}$, indicating that development had proceeded in a manner consistent with observations by Frank \& Leggett (1986) and de Lafontaine \& Leggett (1988). The variance in length increased during the $24 \mathrm{~h}$ experimental period partly as a result of variations in developmental conditions and partly because of the handling associated with rinsing the mesocosms.

The average larval mortality rate due to predation (Z) was 2.23. Larval capelin mortality rates due to predation were strongly correlated with both predator length (Fig. 3, Table 1) and the mean length of the capelin larvae (Fig. 4, Table 1). On average, larger predators were able to capture more prey than smaller ones and larger fish larvae were less vulnerable to predators than smaller fish larvae. Residuals from regression of daily mortality rates due to predation in relation to predator length were significantly correlated with larval length $(\mathrm{r}=-0.56, \mathrm{p}<0.01, \mathrm{n}=23)$. Residuals from the regression of daily mortality rate due to predation using larval capelin length as the independent variable were significantly correlated with predator length $(r=0.43, p<0.05, n=23)$. The combined linear effects of prey and predator length provided a better predictor than either variable taken alone

$$
Z=13.9-2.58 L_{1}+0.046 L_{p}
$$

$(\mathrm{r}=0.75, \mathrm{p}<0.001, \mathrm{n}=23)$ where $L_{1}=$ length of capelin larvae and $L_{p}=$ length of the predator. Standard error of the regression parameters for the intercept, prey and predator lengths $=4.6,0.72$, and 0.020 respec- 
Table 1 Pearson product-moment correlation coefficients and levels of significance for experimental variables in cases when predators were present $(n=23)$

\begin{tabular}{|c|c|c|c|c|c|c|}
\hline & $\begin{array}{c}Z \\
\left(d^{-1}\right)\end{array}$ & $\begin{array}{l}\text { Predator length } \\
\qquad(\mathrm{mm})\end{array}$ & $\begin{array}{l}\text { Initial prey length } \\
(\mathrm{mm})\end{array}$ & Variance in length & $\begin{array}{c}\text { Yolk-sac diameter } \\
(\mathrm{mm})\end{array}$ & $\begin{array}{c}\text { Temperature } \\
\left({ }^{\circ} \mathrm{C}\right)\end{array}$ \\
\hline$Z$ & - & 0.68 & -0.71 & -0.21 & 0.70 & 0.25 \\
\hline Predator length & $\cdots$ & - & -0.42 & 0.43 & 0.31 & 0.39 \\
\hline Initial prey length & $\ldots$ & $?$ & - & 0.36 & -0.92 & -0.09 \\
\hline Variance in length & ns & $?$ & ns & - & -0.46 & 0.94 \\
\hline Yolk-sac diameter & $\cdots$ & ns & $\cdots$ & $\cdot$ & - & 0.18 \\
\hline Temperature & ns & $?$ & ns & $\cdots$ & ns & - \\
\hline
\end{tabular}

tively. Partial regression coefficients $=0.59$ and 0.30 for prey and predator lengths respectively.

One might argue that 5 high points $(Z>4)$ appearing in Figs. 3 \& 4 drive the apparent effect of prey and predator sizes on larval capelin mortality rates. A reanalysis excluding the observations with $Z>4$ produced the same significant results as described above. Both prey and predator lengths had a significant influence on mortality rates. Regression parameters were altered by the exclusion of high points, but the general trends remained.

The significant contribution of both prey and predator lengths to larval capelin mortality rates due to predation led us to ascertain whether their relative size could provide a strong predictive variable. The basis for this model comes from Pearre's (1986) findings that the logarithmic (ratio) niche breadth in fish is independent of fish (predator) length. If correct, this would imply that beyond a predator's optimum prey size [e.g. 5 to $7 \%$ of the predator's length (Kerr 1974)], vulnerability to predation should be a linear function of the logarithm of relative sizes. Furthermore, the ratio of prey-predator sizes may be more readily used in estimating predator-prey interactions in a food web or chain (e.g. Sheldon et al. 1977, Silvert \& Platt 1978).

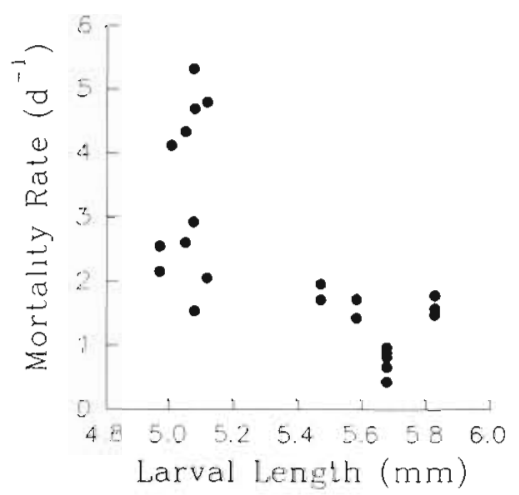

Fig. 4. Mallotus villosus. Mortality rate $(Z)$ in relation to larval capelin length
The natural logarithm of the ratio of larval capelin length $(\mathrm{mm})$ to stickleback length $(\mathrm{mm})$ provides a good predictor of predation rates (Fig. 5)

$$
Z=-7.5-4.5 R
$$

( $\mathrm{r}=-0.66, \mathrm{p}<0.001, \mathrm{n}=23$ ) where $Z=$ instantaneous mortality rate due to predation: $R=$ natural logarithm of the ratio of prey ( $\mathrm{mm}$ ) to predator ( $\mathrm{mm}$ ) lengths; and SE of intercept and slope $=2.42$ and 1.11 respectively. Eq. (4) indicates that a proportional change in prey length had an equal but opposite effect on the mortality rate of capelin larvae due to predation by threespined sticklebacks to an equal proportional change in predator length. The variance explained by Eq. (4) $\left(\mathrm{r}^{2}=0.44\right)$ is weaker than that explained by the multiple regression model using prey and predator lengths (Eq. 3, $\mathrm{r}^{2}=0.57$ ). When the model proposed in Eq. (4) is decomposed into an additive one, the fitted relationship is

$$
Z=16.7+2.26 \ln \left(L_{\mathrm{p}}\right)-13.7 \ln \left(L_{1}\right)
$$

( $r=0.75, p<0.001, n=23$ ) which has an $r^{2}$ similar to that obtained in Eq. (3). Despite the higher $r^{2}$, the

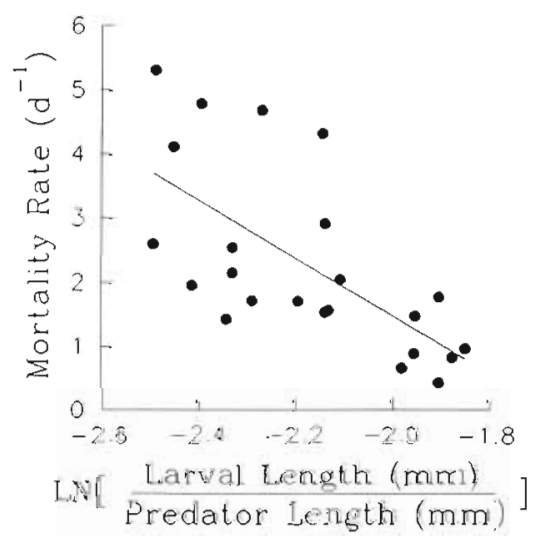

Fig. 5. Mallotus villosus, Gasterosteus aculeatus. Mortality rate (Z) in relation to natural log of larval to predator length ratio 
precision of predicted mortality rates using Eq. (5) is not greatly improved over that of the simpler model (Eq. 4) because of the greater number of parameters estimated in the former (Fig. 6). As a result, we will refer to Eq. (4) in our discussion of capelin larvaestickleback interactions because of the approximately equal precision and the simpler interpretation of preypredator interactions.

Although increasing prey length relative to predator length decreased the impact of sticklebacks on larval fish between experimental trials, analysis of the length. frequency distribution of the survivors within a trial showed that the predators were selecting larger individuals in the experimental mesocosm (Fig. 7). In 6 of the 7 trials with a sufficient sample size of larvae, the length-frequency distribution of larvae that survived in the presence of predators was significantly different from that remaining in the controls, as determined using a Kolmogorov-Smirnov two-sample test. The results clearly show that predation within an experimental mesocosm was more pronounced on the larger individuals.

There is evidence that after accounting for the effects of predator and prey size (Eq. 4), residual mortality rates of larval capelin were influenced by the initial variance in length of capelin larvae (Fig. 8) but were not influenced by other morphological features (i.e. eye diameter, yolk-sac diameter, depth of pectoral girdle). Data in Fig. 8 are not appropriate for correlation or regression analysis because of heterogeneity. When the data are grouped into low $(\vec{x}=0.29$, range: 0.27 to 0.32$)$ and high $(\bar{x}=0.69$, range: 0.64 to 74$)$ cate-

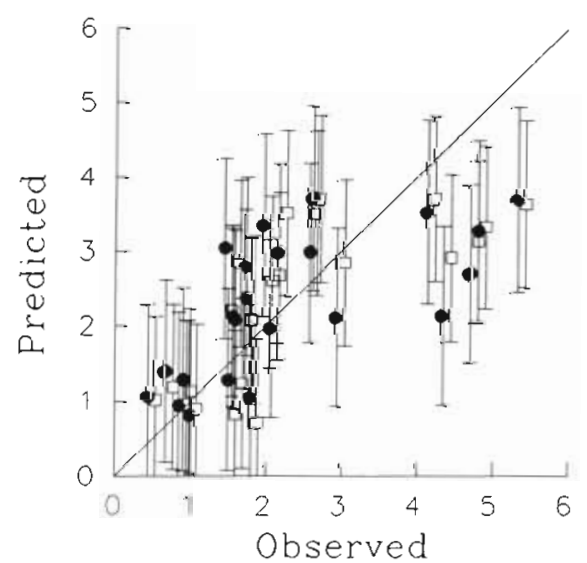

Fig. 6. Mallotus villosus, Gasterosteus aculeatus. Plot of the mortality rates due to predation predicted using Eq. (4) (•) and Eq. (5) ( $\square$ ) in relation to those observed in the experimental trials. Error bars represent the $95 \%$ confidence intervals of the predicted values. The $1: 1$ line is shown for reference purposes. Observed values for predictions using Eq. (5) are slightly offset from the true value to better illustrate the contrast in confidence intervals gories, the average residuals for the 2 variance groups are significantly different (two-tailed $t=4.61, p<0.01$, $\mathrm{n}=23$ ). When the variance in initial length was high, the relative impact of predators was lower. This could be explained by predators tending to attack larger prey that are more effective at avoiding capture (i.e. larger individuals) and thus ingest fewer prey items.

It might be argued that the apparent effects of prey and predator sizes in our experiments are due to satiation of the sticklebacks rather than due to differential capture or escape abilities of predator or prey. To address this issue one can estimate the proportion of the predator's body weight ingested in relation to the prey length/predator length ratio. Wooton (1976) reports a length-weight relationship for three-spine sticklebacks that is

$$
W_{\mathrm{g}}=\left(8.21 \times 10^{-6}\right) L_{\mathrm{g}}^{3.01}
$$

where $W_{g}=$ wet wt $(g)$ and $L_{g}=$ standard length $(\mathrm{mm})$. According to Chellapa et al.'s (1989) data, dry wt is $20 \%$ of wet wt. We have no length-weight relationship for capelin larvae. However, the length-weight relationship for herring (Laurence 1978), a species which is similar in body shape to capelin, is

$$
W_{c}=\left(4.74 \times 10^{-9}\right) L_{c}^{4.29}
$$

where $W_{\mathrm{c}}=$ dry wt and $L_{\mathrm{c}}=$ standard length $(\mathrm{mm})$. From these 2 relationships and the number of prey ingested by the predator (Eq. 2), one can estimate the relative daily ration of each predator [dry wt of prey (in gj/dry wt of predator (in g)]. Fig. 9 shows that the relative ingested ration increases continuously in relation to the ratio of prey and predator lengths. There is no evidence of levelling off, which would be indicative of predator satiation, as the relative size of prey increases. The mean ration per stickleback measured in our experiments was approximately $2 \%$ (range: 0.6 to $4 \%$ ). This is much lower than the average satiation level of $5 \%$ estimated in other studies (Beukema 1968, Manzer 1976, Rajasilta 1980, Allen \& Wooton 1984). These findings suggest that sticklebacks in our experiments were not sated.

\section{DISCUSSION}

Our results are consistent with numerous other studies showing that predators, either vertebrate or invertebrate, can consume a greater number of fish larvae as each predator's size increases (Theilacker \& Lasker 1974, Bailey \& Batty 1984, Brownell 1985, Folkvord \& Hunter 1986, de Lafontaine \& Leggett 1988). However, our results differ from previous studies which 

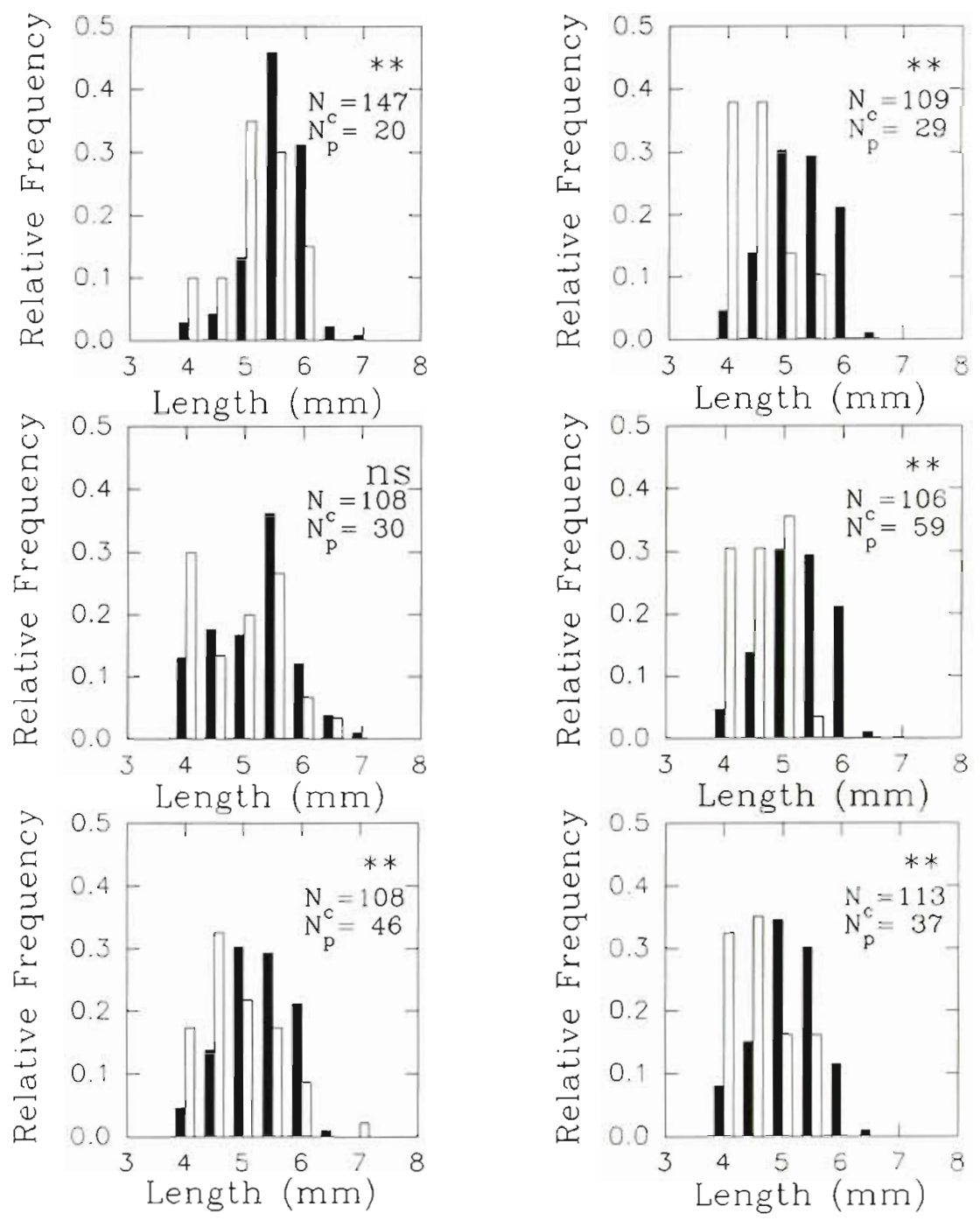

Fig. 7. Mallotus villosus, Gasterosteus aculeatus. Relative length-frequency distribution of larval capelin surviving in absence (black bars) and presence (open bars) of predators, after $24 \mathrm{~h}$ in the experimental mesocosms, from 7 experimental trials. $N_{c}$ and $N_{p}$ represent the no. of larvae from control and experimental mesocosms respectively. Significance levels of the Kolmogorov-Smirnov two-sample test are indicated in the upper right corner of each panel: ns: not significant; ${ }^{\cdots}: \mathrm{p}<0.05$

show that over a given range of predator and prey sizes, vulnerability to predation either increases or decreases in a monotonic manner. We found that the effect of variations in prey size on the probability of being eaten differs when we contrasted size-dependent mortality rates between cohorts (or experimental trials) with those observed within cohorts. Between cohorts, we

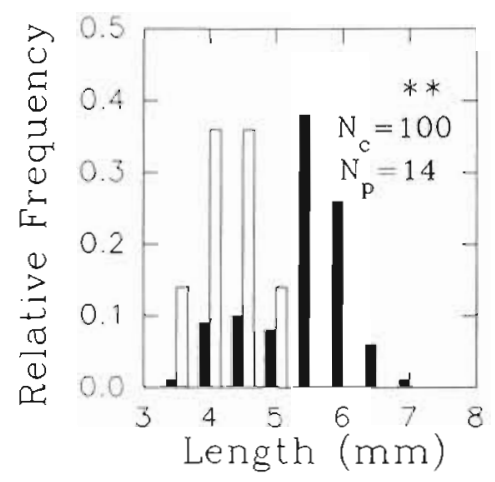

found that increasing prey size, or developmental state, resulted in decreasing predation rates (Fig. 5) whereas within cohorts there was clear evidence of selective removal of the larger larvae by the predator (Fig. 7). We postulate that these contrasting relationships are due to the hierarchy of processes that determine the relationships in predator-prey interactions. 


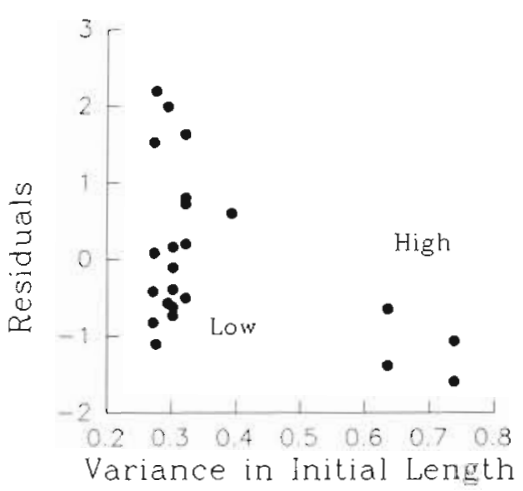

Fig. 8. Mallotus villosus. Residual mortality (Eq. 4) plotted against variance in initial length of capelin larvae used in the experiments

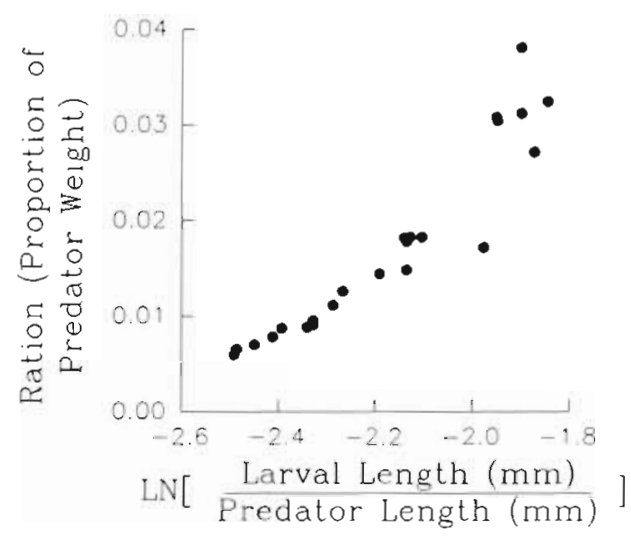

Fig. 9. Mallotus villosus, Gasterosteus aculeatus. Ration, expressed as the proportion of the predator's body weight, in relation to the natural log of prey to predator length ratio

Predation can be viewed as operating on different scales of interaction. When we estimate the predation rate for each cohort (trial), we are providing an integrated measure of all the interactions between the predator and individual larvae. This is the net predation rate on the cohort within each tank. At this scale of interaction, we find that the integrated predation rate $(Z)$ decreases as the mean size of the larvae increases relative to the size of the predator. When we look at the pattern of prey selection within an experimental mesocosm, we are investigating the influence of variations in prey size within the predator's search ambit (i.e. the spatial range the predator can sample within a single cycle of the diurnal foraging rhythm) on the vulnerability of larval fish to sticklebacks rather than the average response of the entire cohort. In a sense, we are looking at the result of the events that have led to the observed pattern in the integrated predation rate. Within the predator's search ambit, the predator is selecting larger prey items because of greater encounter or attack probabilities due to greater activity (Gerritsen \& Strickler 1977) or longer perception distance (e.g. Eggers 1977) relative to smaller prey. Brownell's (1985) results show that over a certain range of prey and predator sizes, detection and attack probabilities increase with increasing size of anchovy larvae Engraulis capensis. As the mean size of larvae is increased (but the variance remains the same), the predator's selection pattern continues to be for larger prey (e.g. due to encounter rates or perception distance). However, interactions with larger prey would be associated with a greater number of failures by the predator because of the decreasing probability of capture with increasing prey size (Folkvord \& Hunter 1986, Pepin et al. 1987, Miller et al. 1988). The consequence of such a selection pattern within the predator's search ambit would be to decrease the average predation rate as the mean size of the prey increased. This would explain the apparent difference in the effect of size between and within experimental mesocosms. Within the predator's search ambit, prey selection can be for larger individuals. However, as the average size of prey increases, the net predation rate will decrease due to greater avoidance. This will result in a decreasing average predation rate as the mean size of larvae increases. Litvak \& Leggett (in press) also found that within groups of capelin larvae of the same age, larger individuals were more likely to be preyed upon than smaller individuals. Similar results were also obtained in freshwater ecosystems where planktivorous fish tend to select larger cladocerans and copepods within the zooplankton assemblage to which they are exposed (Zaret 1972, Zaret \& Kerfoot 1975, O'Brien et al. 1976, Bartell 1982).

The general trend we observed was that as larvae absorbed their yolk and increased in size relative to the predator, the impact of sticklebacks decreased. Such a pattern does not differ substantially from that generally observed for similar-sized invertebrate carnivores (Theilacker \& Lasker 1974, Bailey 1984, Bailey \& Batty 1984, Purcell et al. 1987, de Lafontaine \& Leggett 1988). This suggests that the general differences in vulnerability to different predator types outlined in the introduction were due to differences in relative prey and predator sizes, which influence the predator's probability of feeding on fish larvae.

To assess how predator types differ with respect to their ingestion rates we contrast the results obtained in this study of predation of larval capelin by Gasterosteus aculeatus with the study by de Lafontaine \& Leggett (1988) of predation of larval capelin by Aurelia aurita, a gelatinous zooplankton. De Lafontaine \& Leggett's (1988) study was conducted using $3.2 \mathrm{~m}^{3}$ in situ enclosures 


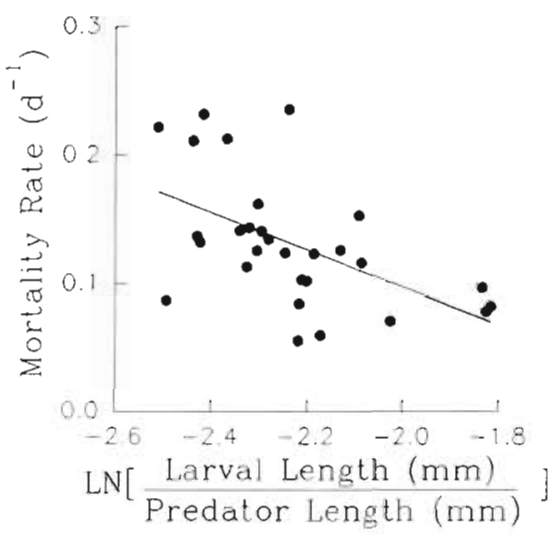

Fig. 10. Mallotus villosus, Aurelia aurita. Mortality rate $\left(\mathrm{d}^{-1}\right)$ in relation to the natural $\log$ of the relative sizes of prey and medusa (Aurelia aurita). The regression model is $Z=$ $-0.20-0.15 R,(\mathrm{r}=0.53, \mathrm{p}<0.001, \mathrm{n}=28)$ where $Z=$ daily instantaneous mortality rate due to predation and $R=$ natural log of the larval length to medusa diameter ratio

The daily mortality rate due to predation by Aurelia aurita in relation to the relative sizes of prey and predator is shown in Fig. 10. By contrasting Figs. 5 \& 10 it is evident that in the range over which the data overlap, predation by sticklebacks will have a greater impact on survival than predation by a gelatinous zooplankter of a similar length. It is also evident that the rate of change in size-dependent mortality is much greater for predation by sticklebacks than for predation by medusae. It has been shown that the probability of capture of fish larvae is independent of predator taxon (Pepin et al. 1987) and principally determined by the relative sizes of prey and predator (Folkvord \& Hunter 1986, Pepin et al. 1987, Miller et al. 1988). The differences in vulnerability of fish larvae to different predator types suggest that there are significant differences in the size-dependent probabilities of encounter and/or attack between predator types.

The average ingestion of 445 capelin larvae predator ${ }^{-1} \mathrm{~d}^{-1}$, for a $50 \mathrm{~mm}$ stickleback $(Z=2.23)$, is significantly higher than the mean ingestion of 60 capelin larvae predator ${ }^{-1} \mathrm{~d}^{-1}$, for a $50 \mathrm{~mm}$ Aurelia aurita $(Z=$ 0.13) estimated from de Lafontaine \& Leggett's (1988) data. However, the contrast in ingestion rates may only reflect differences in the metabolic requirements of the different predator types resulting from their different morphologies. A stickleback, $50 \mathrm{~mm}$ standard length, has a metabolic requirement of approximately $210 \mu \mathrm{l}$ $\mathrm{O}_{2} \mathrm{~h}^{-1}$ at $10^{\circ} \mathrm{C}$ [based on a wet wt of $1.07 \mathrm{~g}$ (Wooton 1976), and assuming that dry wt is $20 \%$ of wet wt (Chellapa et al. 1989) with a respiration rate of approximately $1000 \mu \mathrm{l} \mathrm{O}_{2}(\mathrm{~g} \text { dry } w \mathrm{t})^{-1} \mathrm{~h}^{-1}$ (Oertzen 1984)] whereas a similarly sized medusa has a metabolic demand of approximately 75 to $132 \mu \mathrm{l} \mathrm{O}_{2} \mathrm{~h}^{-1}$ [based on a wet wt of $9 \mathrm{~g}$ wet wt (de Lafontaine \& Leggett 1989), assuming that dry wt is $4 \%$ of wet wt (Beers 1966 , Larson 1986, de Lafontaine \& Leggett 1989), and using Ikeda's (1985) general size and temperature dependent relationship for oxygen uptake by zooplankton or using Biggs' (1977) estimate of oxygen uptake for gelatinous zooplankton, assuming that protein is $8.1 \%$ of dry wt (Cushing et al. 1958) and a $Q_{10}$ of 1.85 (Ikeda 1985)]. Assimilation efficiency was assumed to be equal for both predators (Allen \& Wooton 1983, Reeve et al. 1989). The ratio of prey eaten to metabolic demands (prey eaten $\mathrm{h}^{-1} / \mu \mathrm{lO} \mathrm{O}_{2} \mathrm{~h}^{-1}$ ), which is a measure of the effective growth potential of the predator, is highly in favour of the stickleback when compared with the medusa (0.088 vs 0.024 respectively). This does not support Larson's (1986) suggestion that body form of gelatinous zooplankton has evolved to permit rapid growth given low metabolic demands while allowing them to handle larger prey items. Higher ingestion rates and greater efficiency suggest that a vertebrate predator of a given size may be more effective at preying on fish larvae when contrasted with a gelatinous zooplankter of the same size because of the former's greater relative rate of energy accumulation.

It has been argued in several studies that increased larval size would be beneficial in terms of increasing the offspring's probability of survival because of increased foraging ability (Blaxter \& Hempel 1963, Miller et al. 1988, MacKenzie et al. 1990) or because of reduced vulnerability to predation (Bailey \& Batty 1984, Brownell 1985, Pepin et al. 1987, Miller et al. 1988, Fuiman \& Gamble 1988, Fuiman 1989). By comparison of the results between and within our experiments as well as with the results from other studies, we have demonstrated the existence of variations in the size-dependent vulnerability to predation as a result of predator type, the relative size of larvae and of the predator, and the relative size of larvae within a cohort. The complete reversal of size dependent vulnerability to predation from within to between cohorts (i.e. experiments) suggests that the development of general size-dependent frameworks of the early life history stages of fish (Ware 1975, Silvert \& Platt 1978, Peterson \& Wroblewski 1984, Miller et al. 1988, Beyer 1989, Houde 1989, Pepin 1991, Pepin \& Myers 1991) must consider how the processes of size-dependent prey selection operate with respect to the time and space scales of observation in order to make accurate predictions of population dynamics. For example, predictions based on experimental average predation rates about the individuals which would have survived during the course of each experiment would have been completely incorrect. However, an estimate of the integrated mortality for the cohort placed in the mesocosm would have been reasonably good. One must determine how the individuals within the population 
(cohort) are affected in addition to estimating average mortality rates for a treatment or a set of environmental conditions.

Our analysis using relative prey-predator sizes has shown that when prey length exceeded $7.5 \%$ of the predator's length, for both a vertebrate and an invertebrate predator, increasing prey size resulted in decreasing the impact of the predator. Through our approach we were able to highlight the similarities (i.e. trends) and differences (i.e. rates) for different predators. It is clear from previous work that vulnerability to a predator should follow a dome-shaped function about the mean (Kerr 1974, Pearre 1986, Bailey \& Houde 1989). In order to reconcile our knowledge dealing with the impact of predators on larval fish, future research should consider the results in terms of relative prey-predator sizes. By placing observations into this perspective, it may be possible to understand how the susceptibility to different predators may change as the larvae progress from hatch towards metamorphosis. Furthermore, deviations from preypredator size ratio relationships could then be used to assess the potential effects of condition (e.g. Westernhagen \& Rosenthal 1981) feeding condition (Williams \& Brown 1990), or other features that may influence larval fish activity patterns.

Acknowledgements. C. Alcock provided valuable technical assistance. Comments by R. Laprise and 3 anonymous reviewers were helpful.

\section{LITERATURE CITED}

Alheit, J. (1986). Egg cannibalism versus egg predation: their significance in anchovies. Comm. Meet. int. Coun. Explor. Sea C.M: ICES 1986/H:59

Allen, J. R. M., Wooton, R. J. (1983). Rate of food consumption in a population of three-spine sticklebacks, Gasterosteus aculeatus, estimated from faecal production. Environ Biol. Fish. 8: $157-162$

Allen, J. R. M., Wooton, R. J. (1984). Temporal patterns in diet and rate of food consumption of the three-spine stickleback, Gasterosteus aculeatus, in Llyn Frongoch, an upland Welsh lake. Freshwat. Biol. 14: 335-346

Bailey, K. M. (1984). Comparison of laboratory rates of predation on five species of marine fish larvae by three planktonic invertebrates: effects of larval size on vulnerability. Mar. Biol. 79: 303-309

Bailey, K. M., Batty, R. S. (1983). A laboratory study of predation by Aurelia aurita on larval herring, Clupea harengus: experimental observations compared with model predictions. Mar. Biol. 72: 295-302

Bailey, K. M., Batty, R. S. (1984). Laboratory study of preda. tion by Aurelia aurita on larvae of cod, flounder, plaice and herring: development and vulnerability to capture. Mar. Biol. 83: 287-291

Bailey, K. M., Houde, E. D. (1989). Predation on eggs and larvae of marine fishes and the recruitment problem. Adv. mar. Biol. 26: 1-83
Bakun, A., Parrish, R. H. (1982). Turbulence, transport and pelagic fish in the California and Peru Current systems. Calif. coop. oceanic Fish. Invest. Rep. 23: 99-112

Bartell, S. M. (1982). Influence of prey abundance on size selective predation by bluegills. Trans. Am. Fish. Soc. 111 : $453-461$

Beers, J. R. (1966). Studies of the chemical composition of the major zooplankton groups in the Sargasso Sea off Bermuda. Limnol. Oceanogr. 11: 520-528

Beukema, J. J (1968). Predation by the three-spine stickleback: the influence of hunger and experience. Behaviour 31. $1-126$

Beyer, J (1989). Recruitment stability and survival: simple size-specific theory with examples from the early life dynamics of marine fish. Dana Rep. 7: 45-147

Biggs, D. C. (1977). Respiration and ammonium excretion by open ocean gelatinous zooplankton. Limnol. Oceanogr. 22: $108-117$

Blaxter, J. H. S., Hempel, G. (1963). The influence of egg size on herring larvae (Clupea harengus). J. Cons. perm. int. Explor. Mer 28: 211-240

Brooks, J. L., Dodson, S. I. (1965). Predation, body size, and the composition of the plankton. Science 150:28-35

Brownell, C. L. (1985). Laboratory analysis of cannibalism by larvae of the cape anchovy, Engraulis capensis. Trans. Am. Fish. Soc. 114: 512-518

Chellapa, S., Huntingford, F. A., Strang, R. H.C., Thomson, R. $Y$ (1989). Annual variation in energy reserves in male three-spine sticklebacks, Gasterosteus aculeatus. J. Fish. Biol. 35: 275-286

Checkley, D. M. (1984). Relation of growth and ingestion for larvae of Atlantic herring Clupea harengus and other fish. Mar. Ecol Prog. Ser 18: 215-224

Christensen, V. (1983). Predation by sand eel on herring larvae. Comm. Meet. int. Coun. Explor. Sea C.M: ICES/L:27

Cushing, D. H., Humphrey, G. F., Banse, K., Leavastu, T (1958). Report of the committee on terms and equivalents. Rapp. P.-v. Réun. Cons. int. Explor. Mer 144: 15-16

de Lafontaine, Y., Leggett, W. C. (1987). Effects of container size on estimates of mortality and predation rates in experiments with macrozooplankton and larval fish. Can. J. Fish. Aquat. Sci. 44: 1534-1543

de Lafontaine, Y., Leggett, W. C. (1988). Predation by jellyfish on larval fish: an experimental evaluation employing in situ enclosures. Can. J, Fish. Aquat. Sci. 45: 1173-1190

de Lafontaine, Y., Leggett, W. C. (1989). Changes in size and weight of hydromedusa during formalin preservation. Bull. mar. Sci. 44: 1129-1137

Dickie, L. M., Kerr, S. M., Boudreau, P. R. (1987). Sizedependent processes underlying regularities in ecosystem structure. Ecol. Monogr. 57: 233-250

Eggers, D. M. (1977). The nature of prey selection in planktivorous fish. Ecology 58: 46-59

Folkvord, A., Hunter, J R. (1986). Size-specific vulnerability of northern anchovy (Engraulis mordax) larvae to predation by fishes. Fish. Bull. U.S. 84: 859-869

Frank, K. T., Leggett, W. C. (1981). Prediction of egg development and mortality rates in capelin from meteorological. hydrographic, and biological factors. Can. J. Fish. Aquat. Sci. 38: $1327-1338$

Frank, K. T., Leggett, W. C. (1986). Effect of prey abundance and size on the growth and survival of larval fish: an experimental study employing large volume enclosures. Mar. Ecol. Prog. Ser. 24: 11-22

Fuiman, L. A. (1989). Vulnerability of Atlantic herring larvae to predation by yearling herring. Mar Ecol. Prog. Ser. 51: 291-299 
Fuiman, L. A., Gamble, J. C. (1988). Predation by Atlantic herring, sprat, and sandeels on herring larvae in large enclosures. Mar. Ecol. Prog. Ser. 44:1-6

Fuiman, L. A., Gamble, J. C. (1989). Influence of experimental manipulations on predation of herring larvae by juvenile herring in large enclosures. Rapp. P.-v. Réun. Cons. int. Explor. Mer 191.359-365

Gamble, J. C., Fuiman, L. A. (1987). Evaluation of in situ enclosures during a study of the importance of starvation to the vulnerability of herring larvae to a piscine predator. J. exp. mar. Biol. Ecol. 113: 91-103

Gerritsen, J., Strickler, J. R. (1977). Encounter probabilities and community structure in zooplankton: a mathematical model. J. Fish. Res. Bd. Can. 34: 73-82

Hewitt, R. P., Theilacker, G. H., Lo, N. C.H. (1985). Causes of mortality in young jack mackerel. Mar. Ecol. Prog. Ser. 26: $1-10$

Houde, E. D. (1987). Fish early life dynamics and recruitment variability. Am. Fish. Soc. Symp. Ser. 2: 17-29

Houde, E. D. (1989). Comparative growth, mortality, and energetics of marine fish larvae: temperature and implied latitudinal effects. Fish. Bull. U.S. 87: 471-496

Houde, E. D., Schekter, R. C. S. (1980). Feeding by marine fish larvae: developmental and functional response. Environ. Biol. Fish. 5: 315-334

Hunter, J. R., Dorr, H. (1982). Thresholds for filter feeding in northern anchovy, Engraulis mordax. Calif. coop. oceanic Fish. Invest. Rep. 23: 198-204

Hunter, J. R., Kimbrell, C. A. (1980). Egg cannibalism in the northern anchovy, Engraulis mordax. Fish. Bull. U.S. 78: $811-816$

Ikeda, T. (1985). Metabolic rates of epipelagic marine zooplankton as a function of body mass and temperature. Mar. Biol. 85: 1-11

Kerfoot, W. C. (1987). Cascading and indirect effects. In: Kerfoot, W. C., Sih, A. (eds.) Predation: direct and indirect impacts on aquatic communities. University Press of New England, Hanover, p. $57-70$

Kerr, S. R. (1974). Theory of size distribution in ecological communities. J. Fish. Res. Bd. Can. 31: 1859-1862

Larson, R. J. (1986). Water content, organic content and carbon and nitrogen composition of medusae from the northeast Pacific. J. exp. mar. Biol. Ecol. 99: 107-120

Laurence, G. C. (1978). Larval length-weight relations for seven species of northwest Atlantic fishes reared in the laboratory. Fish. Bull. U.S. 76: 890-895

Litvak, M. K., Leggett, W. C. (1992). Age and size-selective predation on larval fishes: the bigger is better paradigm revisited. Mar. Ecol. Prog. Ser. 81: 13-24

Mackenzie, B. R., Leggett, W. C., Peters, R.H. (1990). Estimating larval fish ingestion rates: can laboratory derived values be reliably extrapolated to the wild? Mar. Ecol. Prog. Ser. 67: 209-225

Manzer, J. I. (1976). Distribution, food and feeding of the three-spine stickleback, Gasterosteus aculeatus, in Great Central Lake, Vancouver Island, with comments on competition for food with juvenile sockeye salmon, Onchorhynchus nerka. Fish. Bull. U.S. 74:647-668

Miller, T J., Crowder, L. B., Rice, J. A., Marschall, E. A. (1988). Larval size and recruitment mechanisms in fishes: toward a conceptual framework. Can. J. Fish. Aquat. Sci. 45: $1657-1670$

Möller, H., (1980). Scyphomedusae as predators and food competitors of larval fishes. Meeresforsch. 28: 90-100

O'Brien, W. J., Slade, N. A., Vinyard, G. L. (1976). Apparent size as a determinant of prey selection by bluegill sunfish (Lepomis macrochirus). Ecology 57: 1304-1310
O'Connell C. P. (1980). Percentage of starving northern anchovy larvae in the sea as estimated by histological methods. Fish. Bull. U.S. 78: 475-489

Oertzen, J. A. v. (1984). Influence of steady-state and fluctuating salinities on the oxygen consumption and activity of some brackish water shrimps and fishes. $J$. exp. mar. Biol. Ecol. 80: 29-46

Pearre, S. Jr (1986). Ratio-based trophic niche breadths of fish, the Sheldon spectrum, and the size-efficiency hypothesis. Mar. Ecol. Prog. Ser. 27. 299-314

Pepin, P. (1991). The effect of temperature and size on development, mortality, and survival rates of the pelagic early life history stages of marine fish. Can. J Fish. Aquat. Sci. 48: $503-518$

Pepin, P., Myers, R. A. (1991). Significance of egg and larval size to recruitment variability of temperate marine fish. Can. J. Fish. Aquat. Sci. 48: 1820-1828

Pepin, P., Pearre, S. Jr, Kosilow, J. A. (1987). Predation on larval fish by Atlantic mackerel, Scomber scombrus, with a comparison of predation by zooplankton. Can. J. Fish. Aquat. Sci. 44: 2012-2018

Peterson, I., Wroblewski, J. S. (1984). Mortality rates of fishes in the pelagic ecosystem. Can. J. Fish. Aquat. Sci. 41. $1117-1120$

Powles, H., Auger F., Fitzgerald G. J. (1984). Nearshore ichthyoplankton of a north temperate estuary. Can. J. Fish. Aquat. Sci. 41. 1653-1663

Purcell, J. E. (1985). Predation on fish eggs and larvae by pelagic cnidarians and ctenophores. Bull. mar. Sci. 37: $739-755$

Purcell, J. E., Siferd, T D., Marliave, J. B. (1987). Vulnerability of larval herring (Clupea harengus pallasi) to capture by the jellyfish Aequorea victoria. Mar. Biol. 94: $157-162$

Rajasilta, M. (1980). Food consumption of the three-spine stickleback (Gasterosteus aculeatus). Annls Zool. fenn. 17: $123-126$

Reeve, M. R., Syms, M. A., Kremer, P. (1989). Growth dynamics of a ctenophore (Mnemiopsis mccradyi) in relation to variable food supply. 1. Carbon biomass, feeding, egg production, growth and assimilation efficiency. J. Plankton Res. 11: 535-552

Royama, $\Upsilon$ (1971). A comparative study of models of predation and parasitism. Res. Popul. Ecol. Suppl. 1: 1-91

Sheldon, R. W., Sutcliffe, W. H., Paranjape, M. A. (1977). Structure of pelagic food chain and relationship between plankton and fish production. J. Fish. Res. Bd Can. 34: $2344-2353$

Silvert, W., Platt, T. (1978). Energy flux in the pelagic ecosystem: a time-dependent equation. Limnol. Oceanogr. 23: 813-816

Smith, P. E., Richardson, S. L. (1977). Standard techniques for pelagic egg and larva surveys. F.A.O. Fish. tech. Circ. No. 175

Theilacker, G. H., Lasker, R. (1974). Laboratory studies of predation by euphausiid shrimps on fish larvae. In: Blaxter, J. H. S. (ed.) The early life history of fish. Springer-Verlag, New York, p. 287-299

Vleit, W. H. v. (1970). Shore and freshwater fish collections from Newfoundland. Natl. Mus. Nat. Sci. (Ottawa) Publ. Zool. 3: $1-30$

Ware, D. M. (1975). Relation between egg size, growth and natural mortality of larval fish. J. Fish. Res. Bd. Can. 32: $2503-2512$

Werner, R. G., Blaxter, J. H. S. (1980). Growth and survival of larval herring in relation to prey density. Can. J. Fish. Aquat. Sci. 37: 1063-1069 
Westernhagen, H. v., Rosenthal, H. (1981). On condition factor measurements in Pacific herring larvae. Helgoländer Meeresunters. 34: 257-262

Williams, D. D., Delbeek, J. C. (1989). Biology of the threespine stickleback, Gasterosteus aculeatus, and the blackspotted stickleback, Gasterosteus wheatlandi, during their marine pelagic phase in the Bay of Fundy, Canada. Environ. Biol. Fish. 24: 33-41

Williams, P. J., Brown J. A. (1990). Developmental changes in foraging-predator avoidance trade-offs in larval lumpfish Cyclopterus Iumpus. Mar. Ecol Prog. Ser. 76: 53-60

This article was submitted to the editor
Wooton, R. J. (1976). The biology of the sticklebacks. Academic Press, London

Wright, D. I., O'Brien, W. J. (1982). Differential location of Chaoborus larvae and Daphnia by fish: the importance of motion and visible size. Am. Midl. Nat. 108: 68-73

Zaret. T (1972). Predators, invisible prey, and the nature of polymorphism in the Cladocera (class Crustacea). Limnol. Oceanogr. 17. 171-184

Zaret, T., Kerfoot, W. C. (1975). Fish predation of Bosmina longirostris: body-size selection versus visibility selection. Ecology 56: 232-237

Manuscript first received: April 23, 1991

Revised version accepted: January 31, 1992 